\title{
A influência das variáveis distância, tamanho dos imóveis e nota agronômica nos preços das terras rurais da região oeste e sudoeste do estado do Paraná
}

Claudinei Chalito da Silva claudineichalito@hotmail.com Paraná - UTFPR, Curitiba, Paraná, Brasil

Simone Aparecida Polli simonep.utfpr@gmail.com Paraná - UTFPR, Curitiba, Paraná, Brasil

\section{RESUMO}

Nas últimas décadas, as terras rurais no Estado do Paraná tiveram enormes aumento dos preços. Uma grande preocupação neste campo de estudos é a compreensão de variáveis que contribuem para a explicação dos preços das terras agrícolas no meio rural. O objetivo deste artigo é testar e analisar três variáveis microeconômicas e confrontar a sua determinação nos preços por hectares dos imóveis. Essas variáveis são quantitativas e referem-se à distância dos imóveis, ao tamanho dos imóveis e à nota agronômica, que mede a qualidade agronômica dos mesmos. Os dados foram obtidos a partir da pesquisa anual do Instituto Nacional de Colonização e Reforma Agrária, no Paraná, por ocasião da investigação para elaboração da Planilha de Preços de Referência de 2018. Os três conjuntos de dados foram submetidos individualmente à análise de correlação linear, tendo como medida o Coeficiente de Correlação ( $r$ ) e também a regressão linear múltipla. A hipótese testada no presente trabalho refere-se à influência das variáveis no preço por hectare dos imóveis rurais. Os resultados foram mais expressivos para a nota agronômica e pouco expressivos para o tamanho dos imóveis e para a distância.
\end{abstract}

PALAVRAS-CHAVE: Preços de terras rurais; Variáveis determinantes; Mercado regional de terras. 


\section{INTRODUÇÃO}

Há décadas, senão séculos, os preços das terras rurais geram intensa dedicação de estudos. Por muito tempo, os preços das terras eram explicados com base na teoria da renda. No entanto, a partir de meados da década de 1950, sobretudo nos Estados Unidos e Europa, os preços das terras passaram a se mostrar muito acima do que a renda da terra explicava.

Nesse sentido, o Paraná, estado onde foi aplicado o presente estudo, é um dos maiores produtores de alimentos e um dos mercados de terras mais dinâmicos do Brasil. Isso reforça a importância desse estado, nas estatísticas nacionais, no setor da economia denominado agronegócio. Sob essa perspectiva, o Paraná é um estado com um forte agronegócio, no entanto, internamente, também apresenta grandes diferenças inter-regionais, em relação: à qualidade dos solos; à infraestrutura, por exemplo, com vias e acessos; ao desenvolvimento social e econômicos; às cadeias produtivas; assim como, ao histórico de colonização. Esses aspectos colaboram para a diferenciação na demanda pela terra, bem como na diferença entre os preços.

O INCRA é um dos órgãos públicos que publica, anualmente, a planilha de preços oficiais de referências das terras rurais. Até o ano de 2014, o INCRA elaborava anualmente a Planilha de Preços de Referência (PPR). Naquele ano foi publicada a Norma de Execução do Incra № 112/2014, que aprovou o Módulo V do Manual de Obtenção de Terras e Perícia Judicial. Essa norma determinou que, além da planilha, deveria ser elaborado um relatório de análise da referida PPR, o qual foi denominado de Relatório de Análise de Mercados de Terras (RAMT). A normatização tem abrangência nacional, mas a elaboração do conjunto RAMT/PPR é de responsabilidades de cada Superintendência Regional, localizada nos estados da federação.

Além do RAMT, essa norma também definiu os critérios para as delimitações geográficas, as quais passaram ser utilizadas a partir de 2016. Essas delimitações são específicas do INCRA, a partir de critérios próprios, dispostos nos normativos. Ademais, são diferenciadas das mesorregiões estabelecidas pelo Instituto Brasileiro de Geografia e Estatística (IBGE) ou outras delimitações semelhantes. Essas delimitações constam no Mapa 1 e são denominadas de Mercados Regionais de Terras (MRT). 
Mapa 1 - Municípios do Mercado Regional de Terras MRT2 - Oeste/Sudoeste

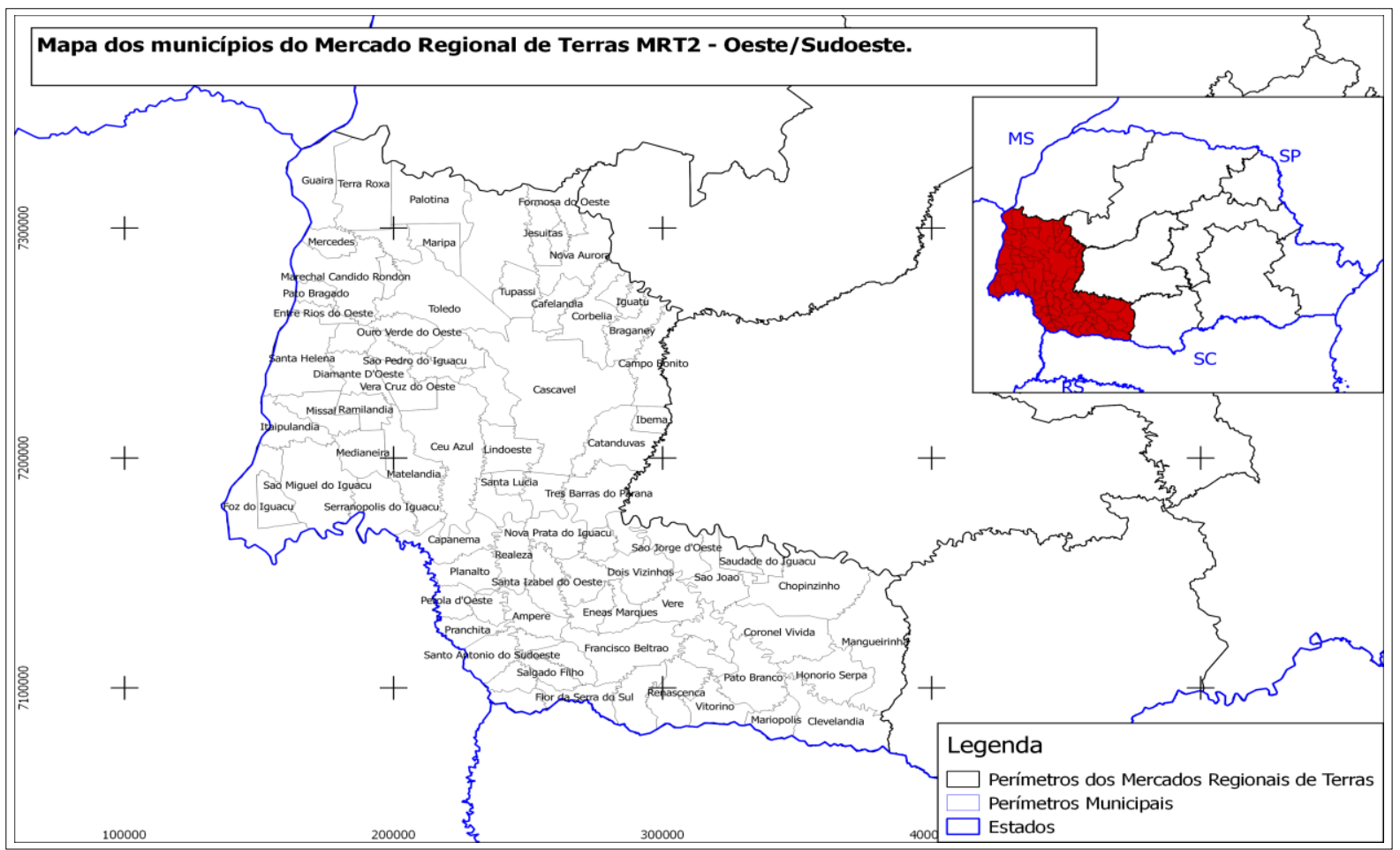

Fonte: Elaborado pelo autor, através de mapa vetorial dos município do IBGE e as delimitações geográficas do INCRA/PR (2018).

Diante desse cenário, o presente trabalho busca: 1) confrontar algumas variáveis que poderão influenciar os preços e 2) calcular a intensidade com a qual isso ocorre. Para tanto, os dados utilizados nesta pesquisa são provenientes da Superintendência Regional do INCRA do Paraná, de acordo com o levantamento de 2018. A região analisada neste estudo é a do MRT 2 - Oeste/Sudoeste (MAPA 1).

Para a análise, as variáveis consideradas foram a distância dos imóveis, o tamanho dos imóveis e a nota agronômica. A respeito da primeira variável, foram analisados apenas os acessos por meio de estrada de chão. Optou-se por confrontar apenas essa extensão e não aquela até os centros urbanos sedes dos municípios ou aos centros urbanos mais próximos, tendo em vista que as observações empíricas mostraram que os acessos pavimentados apresentam pouca influência sobre os preços.

Quanto ao tamanho da área dos imóveis, sabe-se que é um tabu reconhecer que o imóvel rural tem variação na precificação por unidade conforme o tamanho. Já para a Nota Agronômica, foi adotada a metodologia utilizada pelo INCRA, o qual procura, por meio dessa variável, mensurar quantitativamente a qualidade dos imóveis a partir de apenas uma variável, comparar a outros imóveis no momento da avaliação. Dentre as variáveis associadas para o cálculo da Nota Agronômica estão os acessos e a localização dos imóveis; as classes de capacidade de uso, segundo a classificação de Norton; a fertilidade; a suscetibilidade à erosão, dentre outras. Diante disso, é importante ressaltar que a Nota Agronômica é um índice que resulta em um valor que varia de zero $(0,000)$ a um $(1,000)$, sendo que, quanto mais próximo de um, melhor será a qualidade agronômica dos imóveis. 
Outra questão que cabe ser destacada refere-se ao fato de a distância analisada recair sobre os acessos, os quais também compõem a Nota Agronômica. Dessa forma, as análises foram realizadas por intermédio da regressão linear múltipla, método recomendado quando se quer comparar mais de duas variáveis, mas também com as variáveis individuais, por meio do Coeficiente de Correlação (r), não incorrer em redundância de variáveis, como mencionado.

É sabido que muitas variáveis explicam os preços, no entanto, o desafio é identificar quais são, bem como qual a interferência que cada uma na precificação. Assim, não se pretende, de forma alguma, justificar os preços apenas com as variáveis analisadas. Portanto, não é de se espantar caso sejam encontradas correlações baixas para as variáveis estudadas. Veremos adiante, que pelo menos duas destas variáveis, a nota agronômica (que indica a qualidade agronômica dos imóveis) e a distância, estão diretamente vinculadas a teoria da renda, ao relacioná-las com o rendimento e com as melhorias agregadas aos solos. 0 objetivo deste estudo é testar e analisar a influência das variáveis distância, tamanho e qualidade agronômica dos imóveis na determinação dos preços das terras rurais em uma das regiões mais dinâmicas do Estado do Paraná.

\subsection{Caracterização da área de estudo}

A delimitação geográfica adotada para estudo é o MRT 2-Oeste/Sudoeste (MAPA 1). Esse MRT abrange as duas mesorregiões do IBGE Oeste e Sudoeste. Essa área foi escolhida para o estudo em virtude de a amostra de dados ter se mostrado consistente. Além disso, a área foi delimitada para análise por se tratar de uma porção do Estado do Paraná com maior valorização de terras e com maior dinamicidade do mercado, aspectos observados no decorrer do tempo.

\section{REFERENCIAL TEÓRICO}

Apesar de a terra ser uma propriedade relativa, conforme a Constituição da República Federativa do Brasil (CRFB/1988), também é uma mercadoria, logo, pode ser comercializada, alugada ou cedida para utilizações diversas a preço de mercado. Contudo, no contexto histórico nem sempre foi assim.

A partir do momento em que a terra foi desvinculada da propriedade feudal e o ocorreu a centralização do poder ao rei, ela passou a ser considerada mercadoria (MOREIRA, 1995). Conforme Moreira (1995), esse período ocorreu em um momento "de transição", o qual compreendeu as revoluções burguesas europeias. No Brasil, por sua vez, esse processo ocorreu mais tarde, após a Lei n.o 601, de 18 de setembro de 1850, conhecida como Lei de Terras de 1850 (SILVA, 2008).

Nesse sentido, grande parte dos estudos dos determinantes dos preços das terras teve na teoria da renda uma base para a sua compreensão. Segundo Deák (2001), o surgimento da teoria da renda coincide com a decadência das monarquias absolutistas e do feudalismo, bem como com o fortalecimento da burguesia.

Desse modo, a teoria da renda começou a ser formulada, ainda no século XVII, pelos escritos dos mercantilistas e fisiocratas (TELLES; REYDON; FERNANDES, 2018, p. 526). Segundo esses autores (2018), essa teoria prossegue com os pensadores 
clássicos pelo século XVIII e XIX, especialmente Smith, Malthus, Ricardo e mais tarde Marx. Telles, Reydon e Fernandes (2018) complementam que para os autores clássicos "a terra teria seu preço atrelado à renda auferida pelo proprietário em um determinado período de tempo".

Por essa lógica, a teoria da renda evoluiu, por décadas, ou ainda, por mais de um século. Smith negando que a terra fosse a fonte de toda a riqueza e acrescentou a visão de "monopólio de classe sobre a terra" (DEÁK, 2001, p. 61); por sua vez, Malthus propõe a teoria da "Lei da população", tendo em vista que a terra como um recurso natural limitado, bem como a previsão da escassez de alimentos (TELLES; REYDON; FERNANDES, 2018); por outro lado, Ricardo preocupava-se com o comportamento das taxas de juros e o preço regulador dos cereais (TELLES; REYDON; FERNANDES, 2018), logo, propôs a teoria da renda diferencial (PAULANI, 2016, p. 517); por fim, Mill destacava que os preços agrícolas permaneceriam no seu "valor natural" ou então entrariam na situação de "monopólio ou escassez" (TELLES; REYDON; FERNANDES, 2018, p. 530).

Sendo assim, os pensadores clássicos concluíram que o preço da terra era determinado pela renda gerada pela atividade agrícola (TELLES; REYDON; FERNANDES, 2018). Telles, Reydon e Fernandes (2018) prosseguem afirmando que os clássicos acrescentaram que se algumas melhorias fossem feitas no solo, melhoraria também o rendimento da terra, sobretudo em relação à fertilidade e à distância até os centros consumidores. Ainda sobre os preços das terras, Malthus previu o aumento da produção de alimentos, ao aplicar capital e trabalho na terra já em produção, o que traria o que denominou de "retorno decrescente".

Sobre a teoria da renda, Marx ofereceu enorme contribuição aceitando parte das manifestações de seus antecessores, mas aperfeiçoando enormemente esses estudos, sobretudo ao discordar de Ricardo e acrescentar ao conteúdo da renda fundiária a renda diferencial e a renda absoluta (PAULANI, 2016). Conforme Paulani (2016), Marx refaz a leitura do que compõe a renda da terra acrescentando o monopólio como determinante de grande parte dessa renda. Paulani (2016) menciona as tratativas de Marx a respeito dos diferenciais de produtividade, as quais ocorrem por meio daquelas melhorias incorporadas ao solo. Dessa forma, Marx conclui que "o preço da terra é a 'forma capitalizada' de sua renda" (DEÁK, 2001, p. 111).

Para os autores clássicos, a terra ocupava papel principal no processo de produção. Contudo, na dinâmica econômica, os estudos sobre a terra foi perdendo importância para a atividade industrial. Assim, várias das teorias dos pensadores clássicos passaram a ser negadas diante das novas práticas agrícolas e da recuperação e manutenção da fertilidade do solo (TELLES; REYDON; FERNANDES, 2018).

Por essa lógica, o pensamento neoclássico impõe fortes mudanças na visão em relação à terra. Para a teoria neoclássica, o fator 'terra' perde importância dentro do processo de produção, sobretudo com os economistas norteamericanos (TELLES; REYDON; FERNANDES, 2018). Logo, a terra, na expectativa de ganhos futuros, passa a ser um ativo econômico ainda na primeira metade do século XX (TELLES; PALLUDETTO, 2015). Telles e Palludetto (2015) mencionam o componente especulativo, em torno da utilização da terra, pelos agentes econômicos, como reserva de valor. Para a teoria neoclássica, o preço das terras é determinado pela "relação direta com os retornos econômicos das atividades 
produtivas" (TELLES; REYDON; FERNANDES, 2018, p. 535). Apesar dessa mudança na visão do componente 'terra' dentro do processo produtivo, não há diferença em relação aos pensadores clássicos no que tange os preços das terras determinados pelos retornos econômicos das atividades produtivas (TELLES; REYDON; FERNANDES, 2018).

A partir da segunda metade do século XX, em meados da década de 1950, houve um abalo no relativo consenso entre as diversas abordagens teóricas obtidas, até então, sobre "o preço da terra [ser] determinado pelos rendimentos que a mesma pode gerar àquele que dela faz uso" (TELLES; REYDON; FERNANDES, 2018, p. 536). Telles, Reydon e Fernandes (2018) citam o ocorrido de "paradoxo do preço da terra". Nessa lógica, foi observado, nos Estados Unidos, a elevação dos preços das terras muito acima daquilo que os seus rendimentos pudessem justificar. Dessa forma, Telles, Reydon e Fernandes (2018) afirmam que, as teorias aplicadas até aquele momento para os determinantes dos preços das terras, se mostraram inadequadas, sendo assim acrescentaram uma ampla gama de fatores a fim de determinar os preços das terras.

Dentre esses fatores - ou variáveis - mencionados estão "elementos macroeconômicos - tais como a inflação, a taxa de juros -, os programas e políticas governamentais voltados ao setor agropecuário, a pressão exercida pelo processo de urbanização no mercado de terras rurais, entre outros" (TELLES; REYDON; FERNANDES, 2018, p. 537). Por essa lógica, Martinelli e Barros (2009), por exemplo, estudaram o comportamento de variáveis microeconômicas como determinantes dos preços das terras para a região canavieira de Pernambuco, para tanto, utilizaram mais de 15 variáveis, divididas em quantitativas, qualitativas, dicotômicas ou dummies, bem como a variável proxy.

Contemporaneamente, a partir dos anos 2000, Flexor e Leite $(2017$, p. 20) chamam a terra de "ativos fundiários" e estabelecem a seguinte hipótese: de que a demanda por commodities no mercado mundial demanda maior quantidade de terras nos países produtores e exportadores, o que, por sua vez, impõe elevação dos preços desses ativos. Os autores (2017) mencionam também haver uma grande expansão de área de cultivo, atraídos pela demanda mundial e que se não fosse o desenvolvimento tecnológico, esse desenvolvimento seria ainda maior.

No entanto, de acordo com Flexor e Leite (2017), essa expansão ocorreu de maneira desigual; sendo maior em países em desenvolvimento, inclusive com declínio nos países industrializados. Para os autores (2017), envolveu grandes aquisições de terras no processo denominado land grabbing ou "estrangeirização" das terras e uma causa da elevação dos preços das terras agrícolas nos países em desenvolvimento seria este interesse global. Flexor e Leite (2017) mencionam ainda haver uma expansão concentrada na produção de poucos produtos, sendo significativo para o Brasil a soja, o milho e a cana-de-açúcar.

Por esse viés, Flexor e Leite (2017) chamam as últimas três décadas de "novo período", o qual é caracterizado pela forte pressão na expansão da fronteira agrícola. Essa pressão, segundo os autores (2017), é marcada pelos conflitos em terras indígenas; pelas questões ambientais, por exemplo, com a expansão do cultivo da soja para o cerrado e região amazônica; pela compra de terra por estrangeiros; pela forte elevação dos preços das terras; pela tentativa de regulação das atividades do setor agrícola, sobretudo no Uruguai e Argentina; assim como, pela forte inserção internacional sobre ativos estratégicos, como água e minerais. 
É no centro dessa complexidade que os estudos sobre os determinantes dos preços das terras adentraram. A terra passou por enorme transformação enquanto mercadoria e circulação de valor. Logo, surge a necessidade de mensurar algumas variáveis na determinação do seu preço. Portanto, neste estudo, para estruturar os dados e delimitar as áreas geográficas analisadas, foi adotada a metodologia do INCRA. Esse instituto, até o ano de 2014, utilizava a delimitação geográfica das mesorregiões indicadas pelo IBGE. Entretanto, em 2014, foi estabelecida nova delimitação geográfica, determinada por meio do Módulo $\mathrm{V}$ do Manual de Obtenção de Terras, aprovado pela Norma de Execução/INCRA DT/N 112/14, de 12 de setembro de 2014.

\section{METODOLOGIA}

Os dados utilizados neste estudo de caso são oriundos da Superintendência Regional do INCRA no estado do Paraná. A pesquisa realizada pelo INCRA, durante o segundo semestre de 2018, abrangeu todo o estado do Paraná, de acordo com a delimitação geográfica estabelecida pelo INCRA: o MRT (Mercado Regional de Terras). Desse modo, cabe ressaltar que os dados foram obtidos pela autarquia federal conforme determinam os seus normativos legais. Esses dados são provenientes dos imóveis rurais em oferta e dos imóveis rurais transacionados (vendidos) nos últimos seis meses da pesquisa. Sendo assim, optou-se por analisar um MRT mais dinâmico e cujos dados são mais consistentes, como tratado no item 1.1 deste artigo.

Após a coleta dos dados em campo, ocorreram duas adequações, referentes aos negócios realizados com pagamentos a prazo e os dados de imóveis ofertados. Os dados de pagamentos a prazo foram convertidos para o valor presente, por meio da aplicação de uma taxa de $6,5 \%$ ao ano, a qual se refere a Taxa de Juros de Longo Prazo (TJLP) do período. Essa conversão é necessária, pois os valores que serão pagos no decorrer do tempo sofrem diferenças e necessitam de correção da inflação.

A elasticidade, segundo o Módulo $V$ do Manual de Obtenção de Terras e Perícia Judicial, "representa o percentual da diferença entre o provável valor real de venda e aquele estabelecido pelo vendedor no início da negociação" (INCRA, 2014). Logo, para os imóveis em oferta não foram adotados os valores em oferta, mas $\operatorname{sim} 90 \%$ do valor ofertado. Assim, foi aplicado o fator de elasticidade de 0,9 para comparar aos imóveis transacionados (vendidos). Esse procedimento foi executado no programa Calc do LibreOffice e resultou em uma amostra com 109 elementos. Em posse da planilha dos dados aplicados a elasticidade e ajustados os valores presentes, as demais operações foram executadas por meio do Programa R.

Inicialmente, a amostra se mostrou bastante dispersa, com coeficiente de variação de 57,58 \% para o preço, variável (y) dependente. Portanto, a variação dos dados observada nessa variável foi muito destoante; o menor valor por hectare equivale a $\mathrm{R} \$ 10.635,01$ e a $\mathrm{R} \$ 123.416,73$ para o maior valor. As amostras podem apresentar alguns dados verdadeiros, mas por algum motivo são fora do contexto dos preços regionais. Esses dados podem ocorrer, seja por uma oportunidade negociada por valor muito baixo, cujos motivos são os mais diversos, como uma necessidade urgente da venda para abater uma dívida, por exemplo, ou ainda uma 
oferta por valor muito alto, fora do contexto dos preços do entorno. Assim, se justifica aplicar alguns critérios para utilizar apenas os dados mais centrais e comuns dos preços do mercado de terras do entorno.

Assim, a amostra foi submetida ao saneamento para atender coeficiente de variação máxima de $30 \%$. Esse limite de saneamento dos dados atende a NBR 14.453-3, adotado pelo INCRA a partir do Módulo V do Manual de Obtenção de Terras e Perícia Judicial. 0 saneamento excluiu 68 dados discrepantes, resultando em 41 elementos com Coeficiente de Correlação de 22,08 \%.

A Tabela 1 apresenta os dados já saneados, os quais foram submetidos às análises estatísticas.

Tabela 1 - Dados resultantes após o saneamento da amostra

\begin{tabular}{|c|c|c|c|}
\hline Preço (R\$) & Área (ha) & Distância (km) & Nota Agronômica \\
\hline $\mathrm{R} \$ 28.776,14$ & 24,2000 & 2,000 & 0,447 \\
\hline $\mathrm{R} \$ 28.811,43$ & 24,2000 & 0,000 & 0,465 \\
\hline$R \$ 29.265,21$ & 21,7800 & 5,000 & 0,513 \\
\hline $\mathrm{R} \$ 29.427,39$ & 53,2400 & 0,000 & 0,422 \\
\hline $\mathrm{R} \$ 29.728,66$ & 140,3600 & 12,000 & 0,399 \\
\hline $\mathrm{R} \$ 30.904,06$ & 302,5000 & 15,000 & 0,381 \\
\hline $\mathrm{R} \$ 31.849,36$ & 60,5000 & 3,000 & 0,461 \\
\hline $\mathrm{R} \$ 32.728,46$ & 11,4950 & 9,000 & 0,439 \\
\hline $\mathrm{R} \$ 34.061,95$ & 10,8900 & 10,000 & 0,542 \\
\hline $\mathrm{R} \$ 34.154,78$ & 15,7300 & 7,000 & 0,574 \\
\hline $\mathrm{R} \$ 35.025,74$ & 21,7800 & 8,000 & 0,354 \\
\hline$R \$ 35.090,51$ & 13,3100 & 3,000 & 0,383 \\
\hline $\mathrm{R} \$ 35.617,11$ & 370,2600 & 4,000 & 0,391 \\
\hline $\mathrm{R} \$ 39.484,86$ & 17,5208 & 20,000 & 0,500 \\
\hline $\mathrm{R} \$ 39.484,86$ & 22,9174 & 20,000 & 0,455 \\
\hline$R \$ 39.680,69$ & 29,0400 & 0,000 & 0,539 \\
\hline $\mathrm{R} \$ 39.706,74$ & 68,9700 & 1,500 & 0,412 \\
\hline $\mathrm{R} \$ 39.844,48$ & 16,9400 & 4,000 & 0,390 \\
\hline$R \$ 39.897,56$ & 87,1200 & 3,000 & 0,409 \\
\hline$R \$ 39.913,44$ & 19,3600 & 0,800 & 0,649 \\
\hline $\mathrm{R} \$ 41.640,41$ & 28,9916 & 2,000 & 0,544 \\
\hline $\mathrm{R} \$ 41.741,13$ & 121,0000 & 12,000 & 0,403 \\
\hline $\mathrm{R} \$ 42.456,21$ & 15,9720 & 5,000 & 0,465 \\
\hline $\mathrm{R} \$ \mathbf{4 2 . 6 1 9 , 8 3}$ & 198,4400 & 0,000 & 0,520 \\
\hline $\mathrm{R} \$ 42.802,19$ & 108,9000 & 17,000 & 0,460 \\
\hline $\mathrm{R} \$ 43.111,38$ & 25,4100 & 1,000 & 0,418 \\
\hline $\mathrm{R} \$$ 43.217,14 & 24,2000 & 2,000 & 0,552 \\
\hline $\mathrm{R} \$ 43.784,75$ & 65,8240 & 10,000 & 0,480 \\
\hline$R \$ 43.930,86$ & 60,5000 & 3,000 & 0,508 \\
\hline$R \$ 45.933,75$ & 147,6200 & 15,000 & 0,402 \\
\hline $\mathrm{R} \$ 47.045,68$ & 19,3600 & 4,000 & 0,585 \\
\hline $\mathrm{R} \$ 49.514,91$ & 242,0000 & 4,000 & 0,560 \\
\hline $\mathrm{R} \$ 51.265,41$ & 26,6200 & 7,000 & 0,468 \\
\hline $\mathrm{R} \$ \mathbf{5 2 . 4 6 5 , 9 1}$ & 12,9954 & 9,000 & 0,561 \\
\hline $\mathrm{R} \$ 54.913,57$ & 58,0800 & 0,300 & 0,597 \\
\hline $\mathrm{R} \$ 56.076,44$ & 66,0660 & 10,000 & 0,463 \\
\hline $\mathrm{R} \$ 56.406,94$ & 43,5600 & 4,000 & 0,589 \\
\hline $\mathrm{R} \$ 57.846,14$ & 30,4920 & 3,000 & 0,583 \\
\hline $\mathrm{R} \$ 58.094,10$ & 215,2832 & 4,000 & 0,562 \\
\hline
\end{tabular}




\begin{tabular}{cccc}
\hline$R \$ 58.226,29$ & 16,9400 & 8,000 & 0,391 \\
\hline$R \$ 61.617,64$ & 29,7660 & 3,000 & 0,539 \\
\hline & Fonte: INCRA/PR (2018)
\end{tabular}

Com a amostra saneada, calculou-se os coeficientes entre a Nota Agronômica (NA), a distância (km) e o tamanho dos imóveis (em hectare) com a correlação dessas na variável preços. O primeiro método utilizado foi a correlação de Pearson, a qual mede esse grau de explicação por meio do Coeficiente de Correlação (r), conforme a Equação 1:

$$
r=\frac{\sum\left(x_{i}-x\right) \cdot\left(y_{i}-y\right)}{\sqrt{\sum\left(x_{i}-x\right)^{2} \cdot\left(y_{i}-y\right)^{2}}} \quad-1 \leq r \leq+1
$$

Como supracitado, foram consideradas três variáveis determinantes $(\mathrm{x})$, sendo elas a Nota Agronômica (NA), a distância de estrada de chão $(\mathrm{km})$ e o tamanho dos imóveis (ha). Como variável dependente (y), foi considerado o preço por hectare dos imóveis ( $R \$$ ).

Cabe destacar que o coeficiente de correlação $(r)$ varia de -1 a +1 . O valor positivo indica que a variável dependente apresenta dependência linear direta entre as variáveis e o negativo indica dependência linear inversa.

A interpretação do resultado do coeficiente de correlação $(r)$ se deu conforme os seguintes parâmetros (QUADRO 1):

Quadro 1 - Parâmetros para interpretação

\begin{tabular}{|l|l|}
\hline \multicolumn{1}{|c|}{ Coeficiente $(\mathbf{r})$} & \multicolumn{1}{c|}{ Correlação } \\
\hline 1 & Perfeita \\
\hline 0,9 a 1 & Muito forte \\
\hline 0,7 a 0,9 & Forte \\
\hline 0,5 a 0,7 & Moderada \\
\hline 0,3 a 0,5 & Fraca \\
\hline 0,0 a 0,3 & Desprezível \\
\hline 0,0 & Nula \\
\hline
\end{tabular}

\subsection{Análise individual da distância dos imóveis e a correlação com o preço}

Os dados mostram que quanto maior a distância mais empecilhos podem se apresentar, tendo em vista que o acréscimo de quilometragem acarreta a necessidade de manutenção de acessos. Além disso, aumenta a necessidade de infraestrutura, como pontes e bueiros. Em muitos casos, os acessos são compartilhados por poucos usuários ou até por um único imóvel, recaindo sobre o proprietário a responsabilidade de manter em bom estado os acessos para o transporte de máquinas, equipamentos, insumos, assim como da produção. Desse modo, a distância é uma variável que impacta em custos e dificuldades logísticas 
para a atividade agrícola para o imóvel rural. Sendo assim, o esperado é uma correlação inversa, ou seja, um coeficiente negativo.

O cálculo da correlação entre a distância e os preços por hectare dos imóveis resultou numa correlação $(r)$ de $-0,05$. O resultado indica uma correlação negativa, visto que se espera que quanto maior a distância de estrada de chão, menor será o preço por hectare. No entanto, a correlação encontrada é desprezível, quase nula. Isso significa que, para esta amostra, a distância apresenta uma correlação quase nula nos preços. Portanto, poder-se-ia afirmar que, nestes preços, os proprietários não se importam com a distância. O Gráfico 1 apresenta a dispersão desses dados apresentando a relação entre distância e preço.

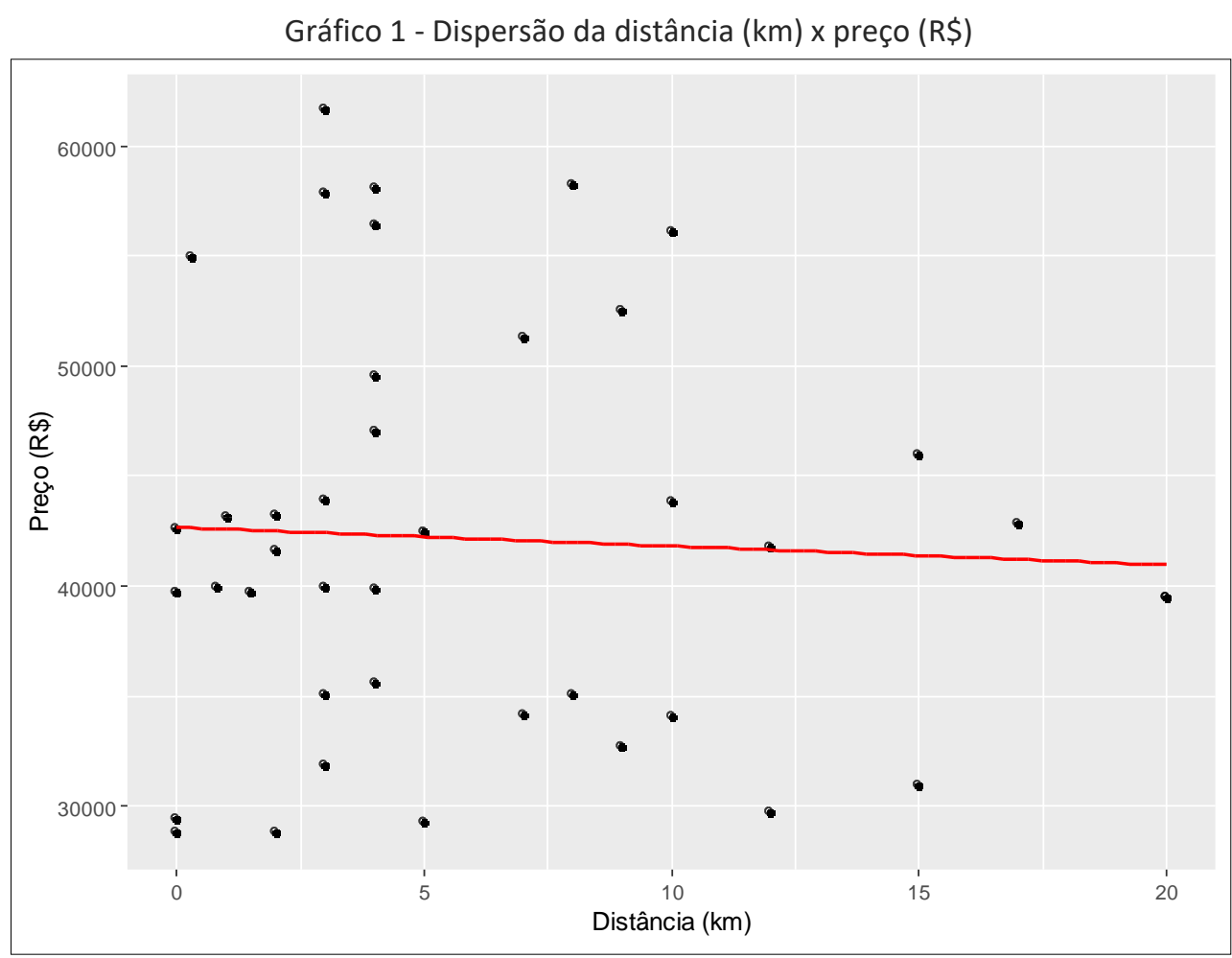

Fonte: INCRA/PR (2018)

\subsection{Análise individual do tamanho dos imóveis e a correlação com o preço}

Sempre se ouviu que o tamanho dos imóveis, quando muito grandes, podem afetar o preço por unidade de área dos imóveis. O que se observa é que a liquidez de mercado pode dar preferência para os imóveis menores, tendo em vista que os maiores aguardam compradores com suporte financeiro suficiente para ter condição de pagamento. Sendo assim, quanto menor a liquidez de mercado, menor o limite de tamanho de imóveis que não se encontra pagador no mercado para o imóvel rural em referência.

Nessa lógica, o cálculo da correlação entre as Notas Agronômicas e os preços por hectare dos imóveis resultou numa correlação $(r)$ de -0.02 . O resultado indica uma correlação negativa, visto que se espera que quanto maior o imóvel, menor será o preço por hectare, no entanto, assim como na variável distância, a 
Logo, mesmo que haja a possibilidade de imóveis muito grandes terem seus preços por hectare afetados em comparação a imóveis menores e com qualidades agronômicas idênticas, é possível afirmar que a amostra não apresentou imóveis rurais com tamanho suficiente para se observar a interferência nos preços. Desse modo, o Gráfico 2 apresenta a dispersão dos dados de acordo com a relação entre o tamanho e o preço dos imóveis.

Gráfico 2 - Dispersão do tamanho (ha) x preço (R\$)

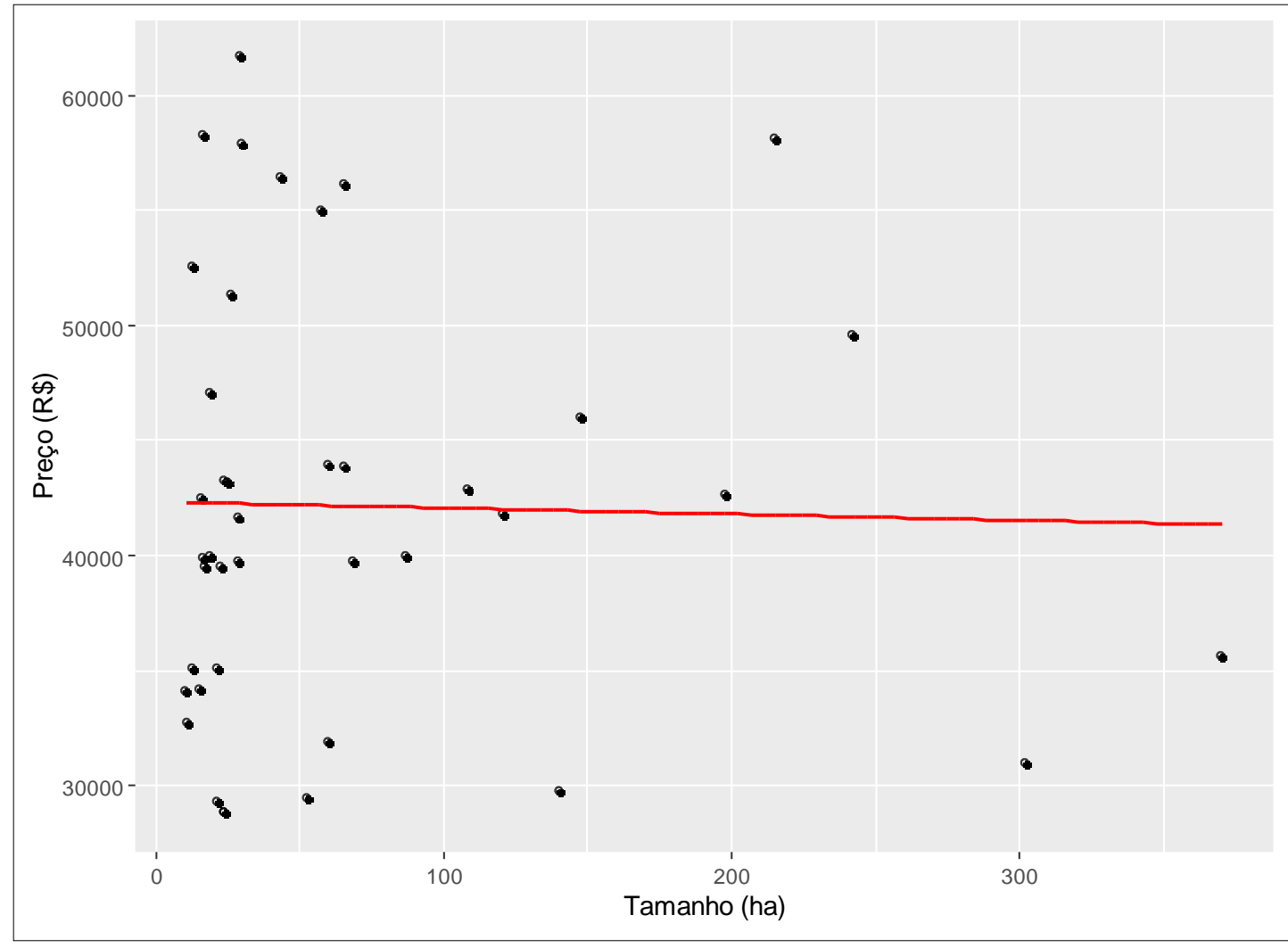

Fonte: INCRA/PR (2018)

\subsection{Análise individual da Nota Agronômica e a correlação com o preço}

A Nota Agronômica é uma variável composta, a qual indica em um único índice a qualidade agronômica para cada imóvel rural da amostra. Dessa forma, o esperado é uma correlação direta, ou seja, um coeficiente positivo.

O cálculo da correlação entre as Notas Agronômicas e os preços por hectare dos imóveis resultou numa correlação ( $r$ ) de 0,41 . Sendo assim, o resultado indica uma correlação positiva, visto que se espera que quanto maior a Nota Agronômica, maior será o preço do imóvel. No entanto, a correlação encontrada foi fraca, conforme os parâmetros determinados no Quadro 1.

O Gráfico 3 apresenta a dispersão dos dados na relação entre a Nota Agronômica e o preço da terra. 
Gráfico 3 - Dispersão da Nota Agronômica (NA) x preço (R\$่)

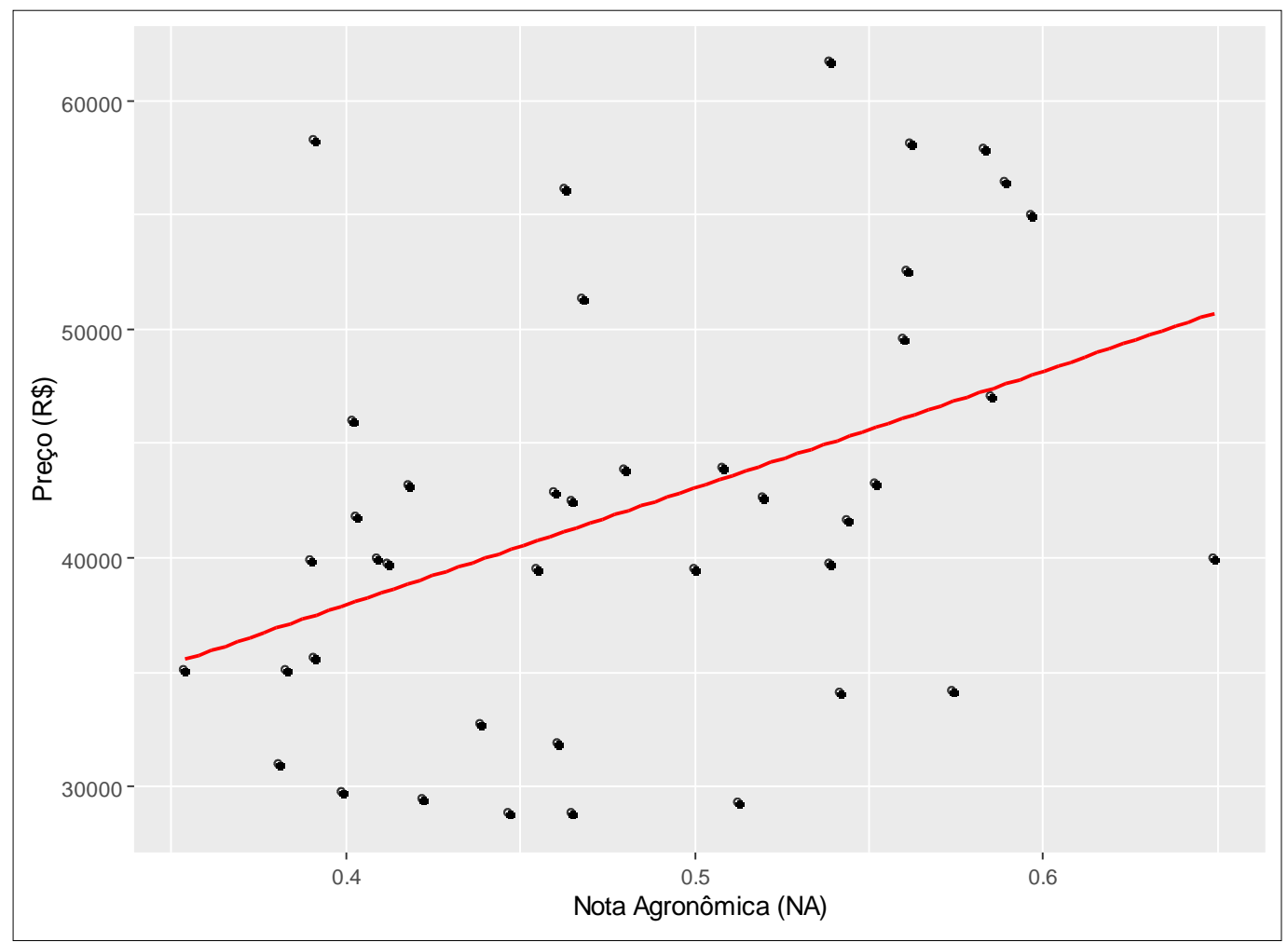

Fonte: INCRA/PR (2018)

\subsection{Regressão linear múltipla}

Quando se analisa mais de uma variável determinante, o recomendado é realizar uma regressão linear múltipla. Essa é dada pela equação:

$$
Y_{i}=\alpha+\beta_{1} X_{1_{i}}+\beta_{2} X_{2_{i}}+e_{i}
$$

Onde:

$$
\begin{aligned}
& y=\text { Preço } \\
& b_{0}=\text { Tamanho do imóvel (hectare) } \\
& b_{1} x_{1}=\text { Distância (km) } \\
& b_{2} x_{2}=\text { Nota Agronômica (NA) }
\end{aligned}
$$

A regressão linear múltipla, com uma variável dependente (preço) e três variáveis determinantes (tamanho, distância e Nota Agronômica) resultou nos resíduos e coeficientes, conforme Figura 1. 
Figura 1 - Análise de regressão múltipla das variáveis 'tamanho', 'distância' e 'nota agronômica'

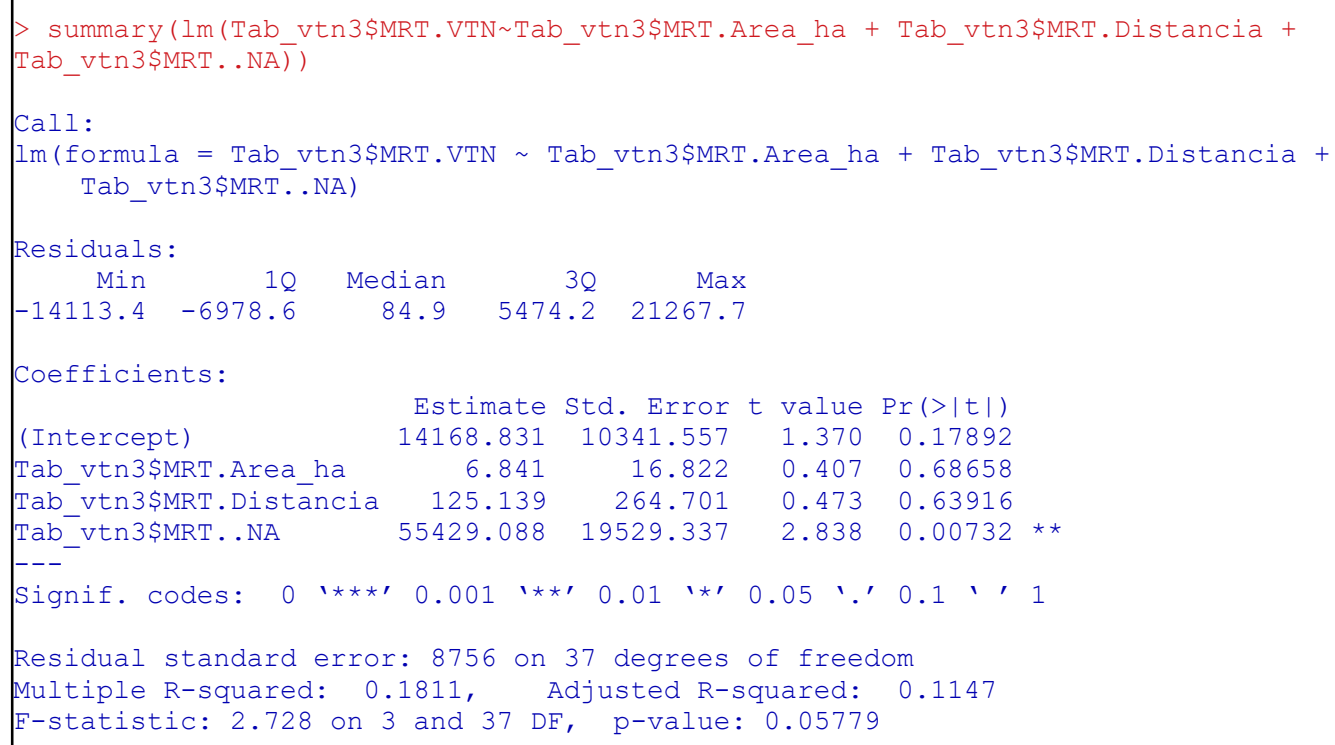

Fonte: elaborado pelo autor, com base nos dados obtidos do INCRA/PR e na análise de regressão processada pelo Programa R (2019).

A Figura 1 possibilita determinar o seguinte modelo:

\section{Preço=14168,831+6,841 xTamanho+ 125,139 xDistância+55429,088 xNA}

O modelo confirma as correlações individuais para as variáveis, sendo desprezível, quase nula, revelando apenas uma contribuição um pouco mais expressiva no preço apenas para a Nota Agronômica.

Verifica-se que o valor $\mathrm{P}$ ( $\mathrm{p}$-value) foi de 0,05779 , ficando, portanto, acima do nível de significância de $5 \%$. Com isso deve-se aceitar a hipótese nula para o teste de regressão, logo, não há correlação entre as variáveis do modelo.

\section{CONCLUSÕES E RECOMENDAÇÕES}

As análises individuais, realizadas com base no coeficiente de correlação ( $r$ ), mostraram a pouca importância das variáveis 'distância' e 'tamanho' sobre os preços dos imóveis rurais e uma leve contribuição da 'Nota Agronômica'. Essa mesma tendência foi confirmada por meio da regressão linear múltipla.

A variável 'Nota Agronômica' mede a qualidade agronômica dos imóveis, mas é uma variável composta por várias outras. Dentre as variáveis estão o acesso, que foi analisada individualmente. Como o acesso, analisado a partir da 'distância' não apresentou evidência de correlação com o preço, mas a 'Nota Agronômica' foi um pouco mais expressiva, uma das possibilidades é decompor essa última a fim de estudar cada um dos componentes. Nesse sentido, a possibilidade de mecanização do solo se torna uma variável que compõe a 'Nota Agronômica', a qual poderá explicar com mais clareza o preço. No entanto, para esta análise, faz-se necessário 
obter resultados mais precisos sobre a quantidade de área mecanizada em cada imóvel rural pesquisado.

Nessa lógica, a constatação acima demonstra que é temeroso afirmar com base em correlações com variáveis compostas. A depender do estudo, a Nota Agronômica pode servir como referência. No entanto, o mercado pode ver potenciais diferentes e confrontar com os custos de adequação. Nessa lógica, a fertilidade natural, por exemplo, pode facilmente ser corrigida com a fertilização química; a presença de empecilhos para a mecanização, como pedregosidade e tocos, em determinados casos pode ser removida e possibilitar a mecanização.

Diante de um cenário agrícola altamente competitivo e com enorme demanda por terra, somado com a busca crescente das commodities agrícolas, as variáveis microeconômicas passam a ter menor importância sobre a formação dos preços das terras rurais. 


\title{
The influence of the variables distance, size of properties and agronomic score in the prices of rural land in the west and southwest of the state of Paraná
}

\begin{abstract}
In recent decades, rural land in the State of Paraná has seen huge price increases. A major concern in this field of study is the understanding of variables that contribute to the explanation of agricultural land prices in rural areas. The objective of this article is to test and analyze three microeconomic variables and to confront their determination in prices per hectare of properties. These variables are quantitative and refer to the distance from the properties, the size of the properties and the agronomic score, which measures their agronomic quality. The data were obtained from the annual survey of the National Institute of Colonization and Agrarian Reform, in Paraná, during the investigation to prepare the Reference Price Spreadsheet of 2018. The three data sets were individually submitted to linear correlation analysis, having the Correlation Coefficient ( $r$ ) as well as the multiple linear regression. The hypothesis tested in the present work refers to the influence of variables on the price per hectare of rural properties. The results were more expressive for the agronomic score and less expressive for the size of the properties and for the distance.
\end{abstract}

KEY WORDS: Rural land prices; Determining variables; Regional land market. 


\section{REFERÊNCIAS}

DEÁK, C. À busca das categorias da produção do espaço. 2001. 213p. Concurso de livre docência - Faculdade de Arquitetura e Urbanismo, Universidade de São Paulo. São Paulo, SP. Disponível em: www.fau.usp.br/docentes/depprojeto/c_deak/CD/3publ/01LD-categ/MC-categesp.pdf. Acesso em: 21 dez. 2018.

FLEXOR, G.; LEITE, S. Mercado de terra, commodities boom e land grabbing no Brasil. In: MALUF, R. S.; FLEXOR, G. (Org.). Questões agrárias, agrícolas e rurais: conjunturas e políticas públicas. 1. ed. - Rio de Janeiro: E-Papers, 2017. p. 20-38.

INCRA. Manual de Obtenção de Terras e Perícia Judicial: Módulo V. Brasília: Gráfica do Incra, 2014. 137p. Disponível em: http://incra.gov.br/sites/default/files/uploads/reforma-agraria/relat-rios-de-anlise-de-mercados-de-terra-ramts-

/norma_de_execucao_incra_112_2014_modulo_v.pdf. Acesso em: 17 fev. 2018.

INCRA. Norma de Execução INCRA/DT/№ 112, de 12 de setembro de 2014. Diário Oficial [da] República Federativa do Brasil, Brasília, DF, 15 out. 2014. Disponível em: http://incra.gov.br/sites/default/files/uploads/reforma-agraria/relat-rios-dean-lise-de-mercados-de-terra-ramts-

/norma_de_execucao_incra_112_2014_modulo_v.pdf. Acesso em: 17 fev. 2018.

MARTINELLI, P. F.; BARROS, K. P. C. dos S. A determinação das variáveis que influência na formação do valor dos imóveis situados na Zona Canavieira de Pernambuco. In: XV COBREAP, Ibape, 15을 Congresso Brasileiro de Engenharia de Avaliações e Perícias. Anais... COBREAP, 2009. Disponível em: http://www.incra.gov.br/media/servicos/publicacao/outras_publicacoes/formac ao_de_valores_de_imoveis_rurais_canavieira_pe.pdf. Acesso em: 24 fev. 2019.

MOREIRA, R. J. Renda da natureza e territorialização do capital: reinterpretando a renda da terra na competição intercapitalista. Estudos Sociedade e Agricultura, v. 3, n. 1, 1995, p. 89-111. Disponível em:

https://revistaesa.com/ojs/index.php/esa/article/view/60/61. Acesso em: 29 jan. 2019.

PAULANI, L. M. Acumulação e rentismo: resgatando a teoria da renda de Marx para pensar o capitalismo contemporâneo. Rev. Econ. Polit., São Paulo, v. 36, n. 3, p. 514-535, set. 2016. Disponível em: http://dx.doi.org/10.1590/010131572016v36n03a04. Acesso em: 30 jan. 2019. 
SILVA, L. O. Terras devolutas e latifúndio: efeitos da lei de 1850. 2ª ed. Campinas: Editora da Unicamp, 2008.

TELLES, T. S.; REYDON, B. P.; FERNANDES, V. B.. Os determinantes do preço das terras agrícolas na história do pensamento econômico. Economia e Sociedade, Campinas, v. 27, n. 2, p. 525-545, ago. 2018. Disponível em http://dx.doi.org/10.1590/1982-3533.2017v27n2art6. Acesso em: 24 jan. 2019.

TELLES, T. S.; PALLUDETO, A. W. A. Preços das terras agrícolas no Brasil entre 1977 e 2010: uma análise dos seus determinantes. In: Congresso da SOBER, 52으, Goiânia, Anais... Brasília: SOBER, 2015. Disponível em:

http://icongresso.itarget.com.br/tra/arquivos/ser.5/1/5751.pdf. Acesso em: 1.o fev. 2019.

Recebido: 23 nov. 2019

Aprovado: $27 \mathrm{fev} .2020$

DOI:10.3895/rbpd.v9n1.11317

Como citar: SILVA, C. C.; POLLI, S. A. A influência das variáveis distância, tamanho dos imóveis e nota agronômica nos preços das terras rurais da região oeste e sudoeste do estado do Paraná. R. bras. Planej. Desenv. Curitiba, v. 9, n. 1, p. 72-88, jan./abr. 2020. Disponível em: <https://periodicos.utfpr.edu.br/rbpd>. Acesso em: XXX.

Correspondência:

Claudinei Chalito da Silva

Av. Sete de Setembro, 3165 - Rebouças - Curitiba, PR

Direito autoral: Este artigo está licenciado sob os termos da Licença CreativeCommons-Atribuição 4.0 Internacional. 